\title{
Article
}

\section{Increased Optoelectronic Quality and Uniformity of Hydrogenated p-InP Thin Films}

Hsin-Ping Wang, Carolin M. Sutter-Fella, Peter Lobaccaro, Mark Hettick, Maxwell Zheng, Der-

Hsien Lien, D. Westley Miller, Charles W. Warren, Ellis T Roe, Mark C Lonergan, Harvey L. Guthrey, Nancy M. Haegel, Joel W. Ager, Carlo Carraro, Roya Maboudian, Jr-Hau He, and Ali Javey

Chem. Mater., Just Accepted Manuscript • DOI: 10.1021/acs.chemmater.6b01257 • Publication Date (Web): 08 Jun 2016

Downloaded from http://pubs.acs.org on June 14, 2016

\section{Just Accepted}

"Just Accepted" manuscripts have been peer-reviewed and accepted for publication. They are posted online prior to technical editing, formatting for publication and author proofing. The American Chemical Society provides "Just Accepted" as a free service to the research community to expedite the dissemination of scientific material as soon as possible after acceptance. "Just Accepted" manuscripts appear in full in PDF format accompanied by an HTML abstract. "Just Accepted" manuscripts have been fully peer reviewed, but should not be considered the official version of record. They are accessible to all readers and citable by the Digital Object Identifier (DOI@). "Just Accepted" is an optional service offered to authors. Therefore, the "Just Accepted" Web site may not include all articles that will be published in the journal. After a manuscript is technically edited and formatted, it will be removed from the "Just Accepted" Web site and published as an ASAP article. Note that technical editing may introduce minor changes to the manuscript text and/or graphics which could affect content, and all legal disclaimers and ethical guidelines that apply to the journal pertain. ACS cannot be held responsible for errors or consequences arising from the use of information contained in these "Just Accepted" manuscripts. 
ABSTRACT: The thin-film vapor-liquid-solid (TF-VLS) growth technique presents a promising route for high quality, scalable and cost-effective InP thin films for optoelectronic devices. Towards this goal, careful optimization of material properties and device performance is of utmost interest. Here, we show that exposure of polycrystalline Zn-doped TF-VLS InP to a hydrogen plasma (in the following referred to as hydrogenation) results in improved optoelectronic quality as well as lateral optoelectronic uniformity. A combination of low temperature photoluminescence and transient photocurrent spectroscopy were used to analyze the energy position and relative density of defect states before and after hydrogenation. Notably, hydrogenation reduces the relative intra-gap defect density by one order of magnitude. As a metric to monitor lateral optoelectronic uniformity of polycrystalline TF-VLS InP, photoluminescence and electron beam induced current mapping reveal homogenization of the grain versus grain boundary upon hydrogenation. At the device level, we measured more than 260 TF-VLS InP solar cells before and after hydrogenation to verify the improved optoelectronic properties. Hydrogenation increased the average open-circuit voltage $\left(V_{\mathrm{OC}}\right)$ of individual TF-VLS InP solar cells by up to $130 \mathrm{mV}$, and reduced the variance in $V_{\mathrm{OC}}$ for the analyzed devices.

\section{INTRODUCTION}

InP is not only used in photocathodes, ${ }^{1}$ photodetectors, ${ }^{2}$ and lasers, ${ }^{3,4}$ but it is also an attractive absorber material for thin-film solar cells due to its suitable optoelectronic properties, such as direct band gap, low unpassivated surface recombination velocity ${ }^{5}$ and high electron mobility. Its band gap of $1.34 \mathrm{eV}$, ideally matches the terrestrial solar spectrum which translates into a theoretically maximum solar conversion efficiency of 31\% (under terrestrial irradiation using a single p-n junction). ${ }^{6}$ Our recently developed thin-film vapor-liquid-solid (TF-VLS) growth platform presents a promising route for the cost-effective fabrication of high quality InP. ${ }^{7}$ In a first demonstration of device applications using the TF-VLS process, as grown InP was doped $p$-type with $\mathrm{Zn}$ by an ex-situ doping process and fabricated into solar cells. Promising efficiencies of up to $12.1 \%$ and a $V_{\mathrm{OC}}$ of $695 \mathrm{mV}$ were obtained using a $n$ - $\mathrm{TiO}_{2} / p$-InP heterojunction architecture. ${ }^{8}$ Despite these promising results, the $V_{\mathrm{OC}}$ is less than what has been 
reported for a InP wafer-based device, which displays a $V_{\text {OC }}$ of $785 \mathrm{mV}$. $^{9}$

One obvious difference between a commercially available single crystal InP wafer and TF-VLS InP is the presence of grain boundaries. In general, grain boundaries can limit the optoelectronic properties of materials due to a high density of dangling bonds and impurity segregation caused by differences in diffusion behavior as compared to the bulk material. ${ }^{10-12}$ Analyzing our TF-VLS $p$-InP via a combination of secondary ion mass spectroscopy (SIMS) and capacitance-voltage $(\mathrm{CV})$ profiling revealed that only $\sim 10 \%$ of the incorporated $\mathrm{Zn}$ was electrically active in our TF-VLS $p$-InP, leading to the possibility that much of the interstitial $\mathrm{Zn}$ accumulates at the interfaces and along grain boundaries. ${ }^{8}$ Moreover, the bulk material quality of single crystal InP can differ from thin-film InP as well, which is caused by structural differences inherent to the growth process such as dislocations, twin boundaries and related defects. ${ }^{13}$

Hydrogen in semiconductors can play an important role by modifying the electrical properties of the material. It does so by passivating native defects and impurities, or inducing electrically active defects. Furthermore, it shows amphoteric behavior in semiconductors, where $\mathrm{H}^{+}$acts as a donor in $p$-type, and $\mathrm{H}^{-}$as an acceptor in $n$-type semiconductors. ${ }^{14,}{ }^{15}$ In III-V semiconductors, hydrogenation of GaAs improves the optoelectronic homogeneity and reduces the surface recombination velocity. ${ }^{16}$ Exposure of single crystalline InP to a hydrogen plasma is an efficient method to passivate shallow acceptors and dislocations. ${ }^{16-}$ 19 The latter, passivation of electrically active dislocations, leads to a reduction in trap states, and is accompanied by a narrowing of their energy distribution. The formation of neutral $\mathrm{Zn}-\mathrm{H}$ complexes is proposed to explain the acceptor passivation. ${ }^{17}, 20$

In this study, the effect of hydrogenation on the optoelectronic properties of Zn-doped TF-VLS InP (TF-VLS InP:Zn) was analyzed by low temperature photoluminescence (PL) measurements and transient photocurrent spectroscopy (TPI). In addition, the effect of hydrogenation on lateral optoelectronic uniformity was investigated using PL and electron beam-induced current (EBIC) mapping. Over all, hydrogenation induced defect passivation and enhanced optoelectronic uniformity translated into a Voc increase accompanied by a narrowing of the Voc distribution in TF-VLS InP solar cell devices.

\section{EXPERIMENTAL SECTION}

Figure 1 present the process schematic of the hydrogenated TF-VLS InP. A $3 \mu \mathrm{m}$ thick In film was evaporated on Mo foil and capped with a $40 \mathrm{~nm} \mathrm{SiO}_{2}$ layer to avoid dewetting of In from the Mo substrate during phosphorization at high temperature. The $\mathrm{SiO}_{2}$ layer confines the film geometry while allowing $\mathrm{P}$ to diffuse into and react with the molten In film. InP growth was carried out at $700{ }^{\circ} \mathrm{C}$ for 20 minutes in a mixed phosphine/hydrogen gas $\left(10 \% \mathrm{PH}_{3}\right.$ diluted in $\left.90 \% \mathrm{H}_{2}\right)$ at a total pressure of 100 Torr. After the growth, the $\mathrm{SiO}_{2}$ cap was etched away by
HF. As-grown InP shows $n$-type behavior caused by donor-like $P$ vacancies $\left(V_{P}\right){ }^{21,22}$

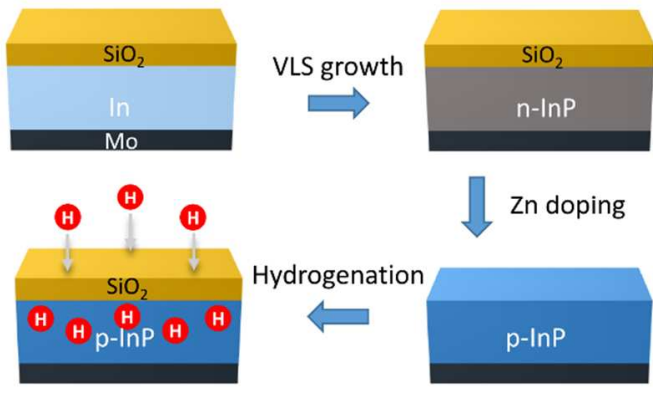

Figure 1. Schematic of the fabrication process of the TFVLS InP with hydrogenation step after Zn doping.

The as-grown InP was converted to $p$-InP by vapor phase solid source doping using $\mathrm{Zn}_{\mathrm{x}} \mathrm{P}_{\mathrm{y}}$ as the $\mathrm{Zn}$ source where the presence of gaseous $\mathrm{P}$ simultaneously suppresses surface decomposition. Within the InP lattice, $\mathrm{Zn}$ can substitute for In or occupy interstitial sites. Substitutional $\mathrm{Zn}$ atoms give rise to the observed $p$-type conductivity. ${ }^{23}$ As outlined above, only $\sim 10 \%$ of the incorporated $\mathrm{Zn}$ is electrically active in our TF-VLS InP:Zn, i.e., Zn on In sites. Thus, a significant proportion of the $\mathrm{Zn}$ possibly forms precipitates or is incorporated as interstitial $\mathrm{Zn}$. These $\mathrm{Zn}$ impurities can introduce deep recombination centers and thereby reduce the carrier diffusion length by increased recombination or by scattering-induced mobility loss. ${ }^{24-26}$

Following ex-situ doping of the InP, the samples were exposed to a H-plasma (Figure 1). Prior to hydrogenation, a $5 \mathrm{~nm}$ thick protective $\mathrm{SiO}_{2}$ layer was deposited on InP to prevent surface damage and InP etching via the formation of $\mathrm{PH}_{3}$ (Figure $\mathrm{S}_{1}$ in the Supporting Information). An inductively coupled plasma (ICP) was used as the plasma source for the hydrogen species. ICP plasma offers the benefit of being a gentle plasma source as compared to DC biased plasmas. Since there is no bias voltage applied, the treatment depends on the diffusivity of $\mathrm{H}$ species in InP. TF-VLS InP:Zn samples were exposed to an optimized condition of H-plasma at $15 \mathrm{~W}$ plasma power and 2 Torr chamber pressure for 5 minutes. The $V_{\mathrm{OC}}$ enhancement under different hydrogenation conditions is shown in Figure $\mathrm{S}_{2}$ in the Supporting Information. Following hydrogenation, the $\mathrm{SiO}_{2}$ cap was etched away by HF. A p$n$ junction is required for some of the measurements presented below, thus, a $15 \mathrm{~nm}$ amorphous $n-\mathrm{TiO}_{2}$ layer, acting as an electron selective contact, was deposited on the InP:Zn film by atomic layer deposition using titanium isopropoxide and water precursors at a temperature of 120 ${ }^{\circ} \mathrm{C}$. Finally, a $55 \mathrm{~nm}$ ITO layer was sputtered on top of the $n-\mathrm{TiO}_{2}$ as the transparent electrode, acting simultaneously as an antireflective layer to complete the stack (compare Figure 5a). EBIC analysis was done at an accelerating voltage of $30 \mathrm{kV}$ and a beam current of $\sim 4 \mathrm{nA}$. PL mapping was performed with a $632.8 \mathrm{~nm}$ HeNe laser at 800 $\mu \mathrm{W}$ at room temperature. A Solar Light $16 \mathrm{~S} 300 \mathrm{~W}$ solar 
simulator was used as the light source at 1-sun intensity (100 $\left.\mathrm{mW} / \mathrm{cm}^{2}, \mathrm{AM} 1.5 \mathrm{G}\right)$ at room temperature to record the $J-V$ curves. TPI spectroscopy, a form of sub-gap absorption spectroscopy, was used to characterize the energetic distribution of optically active defects in the band gap of TF-VLS InP photovoltaic devices. ${ }^{27,}{ }^{28}$ In order to measure a TPI spectrum, a current transient was produced by holding the sample in reverse bias $(-0.5 \mathrm{~V})$ following a $100 \mathrm{~ms}$ filling pulse (+o.2 V). The samples were illuminated with monochromatic light during every other transient, and the TPI signal was calculated from the integrated difference between the illuminated and nonilluminated transients. By scanning the energy of the monochromatic illumination, and normalizing by the incident flux, a spectrum was produced. ${ }^{29}$, 30 Measurements were performed at $80 \mathrm{~K}$.

\section{RESULTS AND DISCUSSION}

The optoelectronic properties of TF-VLS InP:Zn were investigated by low temperature PL. The PL spectra taken at $8 \mathrm{~K}$ on samples before and after hydrogenation (488 $\mathrm{nm} \mathrm{Ar}$ ion laser excitation, $200 \mu \mathrm{W})$, together with Gaussian fits of the data (dotted lines) are shown in Figure 2 a. The fitted peaks are in agreement with previously reported PL spectra and can be attributed to various transitions based on those analyses. From high to low energy, they are band-to-acceptor (B-A) transition at $1.37 \mathrm{eV}$, the donor-to-acceptor (D-A) transition at $1.34 \mathrm{eV}$, a small longitudinal-optical phonon replica (LO) of the B-A transition at $1.32 \mathrm{eV}$, and a broad peak extending from 0.95 to 1.22 $\mathrm{eV}$ (centered around $1.13 \mathrm{eV}$ ) related to various deep levels (DLs). ${ }^{31-34}$

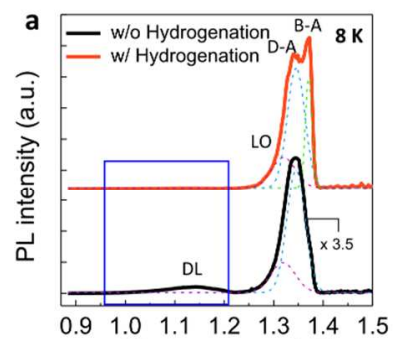

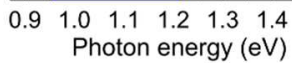
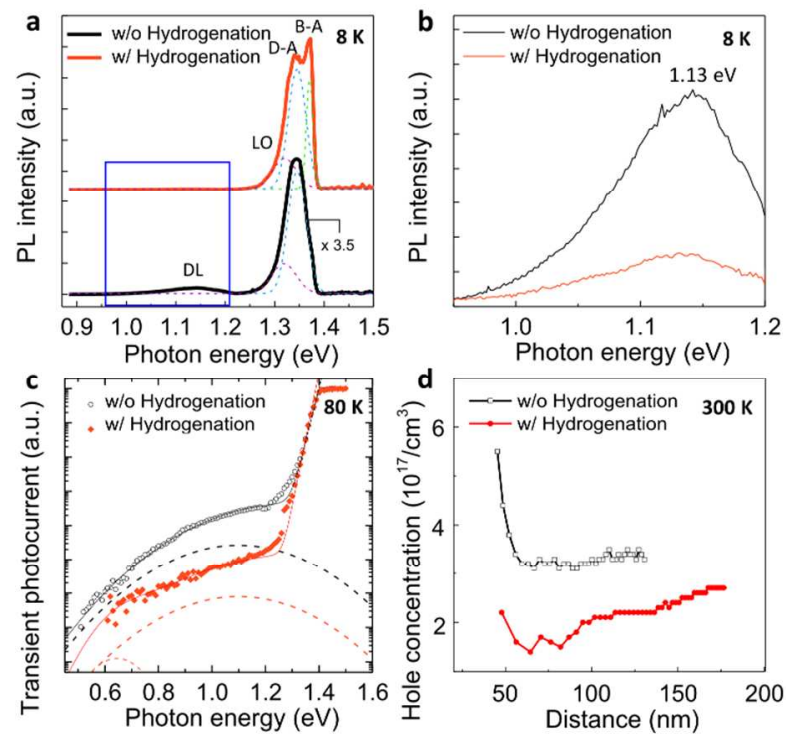

Photon energy (eV)

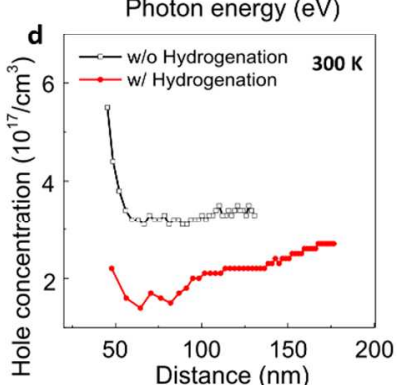

Figure 2. (a) PL spectra of TF-VLS:Zn InP (488 nm Ar ion laser excitation) at $8 \mathrm{~K}$ before and after hydrogenation. The fitted curves (dotted lines) are produced by using multiplepeak Gaussian fitting. (b) Enlargement of the broad DL peak seen in (a). (c) TPI spectra of TF-VLS InP solar cells with and without hydrogenation measured at $80 \mathrm{~K}$ under reverse bias of -0.5 V with filling pulse of $0.2 \mathrm{~V}$. The solid lines represent fits with the integrated sum of two Gaussian defect bands and an exponential band edge. The dashed lines illustrate the underlying density of states. (d) Hole concentration as a function of depth extracted from CV measurements on completed devices before and after hydrogenation.

These DLs can be associated with $\mathrm{V}_{\mathrm{P}}$, interstitial Zn, residual impurities, and their complexes. ${ }^{33,} 35$ After hydrogenation, the absolute PL intensity associated with the DLs drops by a factor of four (Figure $2 \mathrm{~b}$ ), the B-A transition appears next to the D-A transition, and the near band edge transitions ( $\mathrm{D}-\mathrm{A}$ and $\mathrm{B}-\mathrm{A}$ transitions) show a slight intensity increase. The reduction in DL intensity indicates that hydrogenation passivates DL related defect states within the band gap, while the appearance of the BA transition and increased near band edge transition intensity imply reduced non-radiative recombination, thus increased radiative recombination.

The rollover of the exponential bandtail seen in the TPI spectra at high energies (Figure $2 \mathrm{c}$ ) indicates a band gap of $1.41 \mathrm{eV}$ at $80 \mathrm{~K}$. An Urbach energy of $15 \mathrm{meV}$ was extracted from the bandtail slope for both samples. This value compares favorably with Urbach energies reported for other polycrystalline thin-film solar cell materials. Values reported for CIGS, range from 18 to $26 \mathrm{meV}$, for CdTe from 15 to $25 \mathrm{meV}$, and for CZTS from 13 to 31 meV. ${ }^{27-30}$ At energies below the bandtail, the spectra of both samples are well fitted by the sum of two defect transitions occurring at 0.64 and $1.10 \mathrm{eV}$. For the sample without hydrogenation, the defect transition at $1.10 \mathrm{eV}$ dominates the sub-gap absorption. The magnitude of the $1.10 \mathrm{eV}$ defect response was reduced by a factor of $\sim 30$ after hydrogenation. The energetic location of this transition and its reduced intensity after hydrogenation are in good agreement with the diminished DL response seen in the low temperature PL spectra.

Following the defect study, the effect of hydrogenation on the net hole concentration in InP:Zn was analyzed by $\mathrm{CV}$ measurements. To reduce the series resistance, a 100 $\mathrm{nm}$ Au layer was deposited on top of the completed devices ( $\mathrm{Au} / \mathrm{ITO} / n-\mathrm{TiO}_{2} / p$-InP/Mo). A 1 x $1 \mathrm{~mm}^{2}$ active area is defined by patterning the Au/ITO using lithography. Figure $2 \mathrm{~d}$ illustrates the hole concentration in TF-VLS InP:Zn before and after hydrogenation. After hydrogenation, there is a slight decrease in hole concentration, from $\sim 3.5 \times 10^{17} \mathrm{~cm}^{-3}$ in the untreated sample to $\sim 2 \times 10^{17} \mathrm{~cm}^{-3}$ in the hydrogenated sample. This slight reduction in hole concentration after hydrogenation was observed consistently in more than 10 samples, indicating a statistical difference. Moreover, the hole concentration at the surface is about three times lower after hydrogenation. Zn accumulation at the InP surface might limit the electron transport from InP to $\mathrm{TiO}_{2}$ due to an unfavorable band bending, which could lead to high charge carrier recombination, resulting in a Voc loss. ${ }^{8} 23$ The beneficial reduction in hole concentration after hydrogenation could be explained by a neutralization reaction where substitutional $\mathrm{Zn}$ ( $\mathrm{Zn}^{-}$acceptor) forms an electrically neutral complex with hydrogen: $\mathrm{H}^{+}+\mathrm{Zn}^{-} \rightarrow(\mathrm{ZnH})^{\mathrm{o}}{ }^{17,36}$ 
Next, the influence of hydrogenation on charge carrier collection in the completed solar cell devices was investigated by EBIC top-view mapping. In the EBIC technique, the electron-hole pairs are generated by scanning the electron beam across the sample, and are separated by the built-in electric field. ${ }^{37}$ Figures $3 a-c$ present a top-view SEM image and the EBIC maps of TF-VLS InP devices with and without hydrogenation, respectively. The image intensity represents the local collection efficiency of charge carriers generated by the sample under scanning electron beam excitation at each pixel. Bright areas in the EBIC images indicate higher collection efficiency of minority carriers.

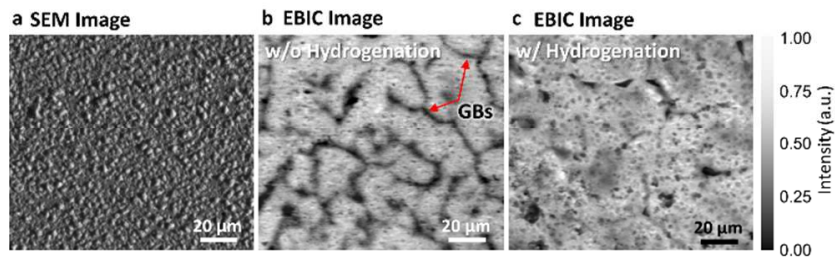

Figure 3. (a) SEM top view image of a TF-VLS InP solar cell. (b), (c) Top view EBIC images of TF-VLS InP solar cells without and with hydrogenation. The charge carrier collection is visualized by the EBIC maps. Bright areas indicate higher collection efficiency of minority carriers. Grain boundaries are visible as dark lines.

The dark lines in the image of the sample before hydrogenation (Figure $3 \mathrm{~b}$ ) depict poor carrier collection along grain boundaries likely due to a higher concentration of non-radiative recombination centers. ${ }^{38}$ Figure $3 \mathrm{c}$ shows that hydrogenation helps to improve charge carrier collection over grain boundaries. One possible explanation for this is that most of the electrically active $\mathrm{Zn}$ or other impurities that segregate along grain boundaries, ${ }^{39}$ are neutralized by the hydrogenation, thus improving carrier transport and collection. The neutralization mechanism could be interpreted by hydrogen bonding to electrically active $\mathrm{Zn}$ or impurities, via the formation of electrically inactive neutral complexes, which passivate the active grain boundaries. ${ }^{17,36}$

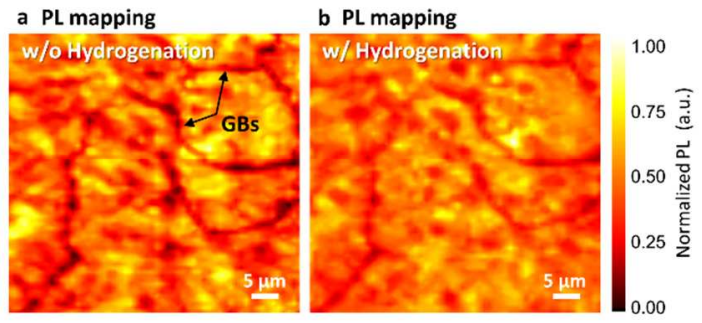

Figure 4. Room-temperature PL mapping of TF-VLS InP:Zn on the same area (HeNe laser excitation source at $632.8 \mathrm{~nm}$ ) (a) before and (b) after hydrogenation. The PL intensities are normalized to the maximum intensity of each PL map and the standard deviation before and after hydrogenation are 130 and 63 counts, respectively.

We then studied the optical uniformity of the material via PL mapping. Figure 4 shows normalized PL maps of the TF-VLS InP:Zn before and after hydrogenation recorded at the same location on the film. After hydrogenation, the initially dark grain boundaries show a relative increase in PL signal. Consequently, the PL signal becomes more uniform over the mapped area, resulting in a reduced standard deviation. In combination with the EBIC analysis, this result leads to the conclusion that hydrogenation helps to form optoelectronically more benign grain boundaries.

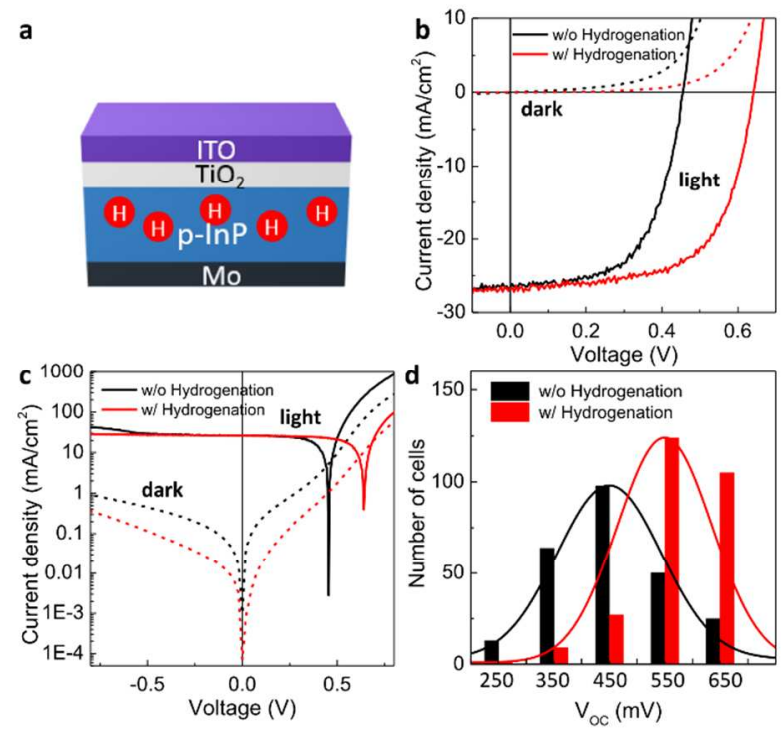

Figure 5. (a) Schematic of the InP solar cell device stack (ITO/n- $\mathrm{TiO}_{2} / p$-InP/Mo). (b) $J-V$ characteristic for TF-VLS InP solar cells with and without hydrogenation under simulated 1 sun illumination (solid line) and in the dark (dash line) at room temperature. Cell area was $0.5 \times 0.5 \mathrm{~mm}^{2}$. (c) Logarithmic plot of (b). The reverse currents are plotted as positive values. (d) Histogram of the $V_{\mathrm{OC}}$ distribution of TFVLS InP solar cells with and without hydrogenation. The $V_{\text {OC's }}$ are binned into $100 \mathrm{mV}$ intervals. The fitted curves are produced by Gaussian fitting.

The influence of hydrogenation at the device level is depicted in Figure 5. Figure 5a illustrates a schematic of the device stack and Figure $5 \mathrm{~b}$ depicts the dark and illuminated current density versus voltage $(J-V)$ measurements. From the $J-V$ curves of an average device under illumination, one can see that the $V_{\mathrm{OC}}$ shows pronounced improvements from 455 to $635 \mathrm{mV}$ after hydrogenation. One reason for the clear $V o c$ increase is the significant suppression of dark current after hydrogenation (Figure 5c) which is almost up to one order of magnitude lower compared to the untreated sample. Moreover, the shunt resistance of $456 \Omega \mathrm{cm}^{2}$ increases to $2837 \Omega \mathrm{cm}^{2}$, which is extracted by fitting the slope past short-circuit from the dark current.

In a polycrystalline material, the shunting behavior could be caused by two main reasons: the present of grain boundaries or highly localized shunt regions. ${ }^{40}$ Grain boundaries are a likely origin of shunt paths.$^{41}$ If the grain boundaries are type inverted, they directly connect the $n$ type $\mathrm{TiO}_{2}$ to the metallic back contact, causing a leakage 
current. After hydrogenation of TF-VLS InP, the shunt resistance and $V_{\mathrm{OC}}$ increase dramatically, indicating the electronic activity of grain boundaries and localized defects is passivated by hydrogen, suppressing extensive dark current flow.

Further analysis of the $J-V$ measurements, reveals almost the same $J_{\mathrm{SC}}\left(26.6\right.$ and $\left.26.7 \mathrm{~mA} / \mathrm{cm}^{2}\right)$ but improved FF from $59 \%$ to $64 \%$ related to the significant $V_{\text {OC }}$ and shunt resistance increase. This results in a conversion efficiency of $10.8 \%$ for the hydrogenated device, a marked improvement from $7.1 \%$ before hydrogenation.

Figure 5 d illustrates the $V_{\mathrm{OC}}$ distribution of 267 TF-VLS InP solar cells with their Gaussian fits (that serve as a guide for the eye) before and after hydrogenation to verify the improved optoelectronic properties. More precisely, a histogram is shown with the experimental $V_{\mathrm{OC}}$ values binned by a $100 \mathrm{mV}$ window. With hydrogenation, the average $V_{\mathrm{OC}}$ is $570 \mathrm{mV}$ compared to an average of $441 \mathrm{mV}$ without hydrogenation. The corresponding standard deviation dropped to $83 \mathrm{mV}$ compared to a standard deviation of $118 \mathrm{mV}$ without hydrogenation. Although the conversion efficiency does not overcome the reported record device performance, ${ }^{8}$ this finding reinforces the idea that hydrogen passivation significantly enhances optoelectronic uniformity accompanied by a narrowing of the Voc distribution in TF-VLS InP solar cell devices.

\section{CONCLUSION}

In conclusion, we have demonstrated that hydrogenation is an effective method to increase the optoelectronic quality and the lateral optoelectronic uniformity of TFVLS InP:Zn. Low temperature PL measurements in combination with transient photocurrent spectroscopy showed the reduction of sub-band gap states. Electrical $\mathrm{CV}$ measurements revealed a decrease in net bulk and surface hole concentration after hydrogenation, thus supporting the formation of electrically neutral $\mathrm{Zn}-\mathrm{H}$ complexes $(\mathrm{ZnH})^{\circ}$. Additionally, PL and EBIC mapping provided evidence for more uniform charge carrier collection after hydrogenation, suggesting that hydrogenation results in grain boundaries that are more electrically benign. The higher optoelectronic quality and uniformity directly translate to an average Voc enhancement of more than $100 \mathrm{mV}$ as well as a reduction in Voc variation from sample-to-sample. This result outlines a promising method for the improvement of nonepitaxial III-V thin-films for future optoelectronic applications.

\section{ASSOCIATED CONTENT}

\section{Supporting Information}

The Supporting Information is available free of charge on the ACS Publications website.

Effect of $\mathrm{SiO}_{2}$ cap protection. $J-V$ of InP with and without $\mathrm{SiO}_{2}$ cap protection, degradation of the surface due to reaction of phosphorus with hydrogen and the subsequent formation of $\mathrm{PH}_{3}$; Effect of hydrogen concentration. $V_{\mathrm{OC}}$ enhancement under different hydrogenation conditions, including different power and exposure times.

\section{AUTHOR INFORMATION}

\section{Corresponding Author}

*E-mail: ajavey@eecs.berkeley.edu

*E-mail: jrhau.he@kaust.edu.sa

\section{Author Contributions}

All authors have given approval to the final version of the manuscript.

$\nabla$ These authors contributed equally.

Notes

The authors declare no competing financial interest.

\section{Funding Sources}

Any funds used to support the research of the manuscript should be placed here (per journal style).

Notes

Any additional relevant notes should be placed here.

\section{ACKNOWLEDGMENT}

Materials characterization and growth was supported by the Electronic Materials Program funded by the Office of Science, Office of Basic Energy Sciences, of the U.S. Department of Energy under Contract No. DE-ACo2-05CH11231. Device fabrication was supported by the Department of Energy through the Bay Area Photovoltaic Consortium under Award Number DE-EEooo4946. J.-H. H. acknowledges KAUST and National Science Council of Taiwan (NSC 102-2911-I-002-552). C.M. S.-F. acknowledges financial support from the Swiss National Science Foundation ( $\left.\mathrm{P}_{2} \mathrm{EZP} 2 \_155586\right)$.

\section{REFERENCES}

(1) Hettick, M.; Zheng, M.; Lin, Y.; Sutter-Fella, C. M.; Ager, J. W.; Javey, A. Nonepitaxial Thin-Film InP for Scalable and Efficient Photocathodes. J. Phys. Chem. Lett. 2015, 6, 2177-2182.

(2) Beling, A.; Campbell, J. C. InP-Based High-Speed Photodetectors. J. Lightwave Technol. 2009, 27, 343-355.

(3) Li, K.; Sun, H.; Ren, F.; Ng, K. W.; Tran, T. T. D.; Chen, R.; Chang-Hasnain, C. J. Tailoring the Optical Characteristics of Microsized InP Nanoneedles Directly Grown on Silicon. Nano Lett. 2014, 14, 183-190.

(4) Haruhisa, S.; Ken-ichi, I.; Chiyuki, K.; Yasuharu, S. GaInAsP/InP Surface Emitting Injection Lasers. Jpn. J. Appl. Phys. 1979, 18, 2329-2330.

(5) Wallentin, J.; Anttu, N.; Asoli, D.; Huffman, M.; Åberg, I.; Magnusson, M. H.; Siefer, G.; Fuss-Kailuweit, P.; Dimroth, F.; Witzigmann, B.; Xu, H. Q.; Samuelson, L.; Deppert, K.; Borgström, M. T. InP Nanowire Array Solar Cells Achieving 13.8\% Efficiency by Exceeding the Ray Optics Limit. Science 2013, 339, 1057-106o.

(6) Henry, C. H. Limiting Efficiencies of Ideal Single and Multiple Energy Gap Terrestrial Solar Cells. J. Appl. Phys. 1980, 51, 4494-4500.

(7) Kapadia, R.; Yu, Z.; Wang, H.-H. H.; Zheng, M.; Battaglia, C.; Hettick, M.; Kiriya, D.; Takei, K.; Lobaccaro, P.; Beeman, J. W.; Ager, J. W.; Maboudian, R.; Chrzan, D. C.; Javey, A. A Direct Thin-Film Path Towards Low-Cost Large-Area III-V Photovoltaics. Sci. Rep. 2013, 3, 2275.

(8) Zheng, M.; Wang, H. P.; Sutter-Fella, C. M.; Battaglia, C.; Aloni, S.; Wang, X.; Moore, J.; Beeman, J. W.; Hettick, M.; Amani, M.; Hsu, W. T.; Ager, J. W.; Bermel, P.; Lundstrom, M.; He, J. H.; Javey, A., Thin-Film Solar Cells with InP Absorber Layers Directly Grown on Nonepitaxial Metal Substrates. Adv. Energy Mater. 2015, 5, 1501337. 
(9) Yin, X.; Battaglia, C.; Lin, Y.; Chen, K.; Hettick, M.; Zheng, M.; Chen, C. Y.; Kiriya, D.; Javey, A. 19.2\% Efficient InP Heterojunction Solar Cell with Electron-Selective $\mathrm{TiO}_{2}$ Contact. ACS Photonics 2014, 1, 1245-1250.

(10) Thompson, K.; Booske, J. H.; Larson, D. J.; Kelly, T. F. Three-Dimensional Atom Mapping of Dopants in Si Nanostructures. Appl. Phys. Lett. 2005, 87, 052108.

(11) Thompson, K.; Bunton, J. H.; Kelly, T. F.; Larson, D. J. Characterization of Ultralow-Energy Implants and Towards the Analysis of Three-Dimensional Dopant Distributions Using Three-Dimensional Atom-Probe Tomography. J. Vac. Sci. Technol. B 2006, 24, 421-427.

(12) Johnson, N. M.; Biegelsen, D. K.; Moyer, M. D. Deuterium Passivation of Grain-Boundary Dangling Bonds in Silicon Thin Films. Appl. Phys. Lett. 1982, 40, 882-884.

(13) Friedrich, J.; Kallinger, B.; Knoke, I.; Berwian, P.; Meissner, E. Crystal Growth of Compound Semiconductors with Low Dislocation Densities, 2oth Indium Phosphide and Related Materials (IPRM), 2008, 1-6.

(14) Van de Walle, C. G.; Neugebauer, J. Hydrogen in Semiconductors. Annu. Rev. Mater. Res. 2oo6, 36, 179-198.

(15) Van de Walle, C. G.; Neugebauer, J. Universal Alignment of Hydrogen Levels in Semiconductors, Insulators and Solutions. Nature 2003, 423, 626-628.

(16) Omeljanovsky, E. M.; Pakhomov, A. V.; Polyakov, A. Y. Hydrogen Passivation of Defects and Impurities in GaAs and InP. J. Electron. Mater. 1989, 18, 659-670.

(17) Chevallier, J.; Jalil, A.; Theys, B.; Pesant, J. C.; Aucouturier, M.; Rose, B.; Mircea, A. Hydrogen Passivation of Shallow Acceptors in p-Type InP. Semicond. Sci. Technol. 1989, 4, 87-90.

(18) Dautremont-Smith, W. C.; Lopata, J.; Pearton, S. J.; Koszi, L. A.; Stavola, M.; Swaminathan, V. Hydrogen Passivation of Acceptors in p-InP. J. Appl. Phys. 1989, 66, 1993-1996.

(19) Chatterjee, B.; Ringel, S. A.; Sieg, R.; Hoffman, R.; Weinberg, I. Hydrogen Passivation of Dislocations in InP on GaAs Heterostructures. Appl. Phys. Lett. 1994, 65, 58-60.

(20) McMurray Jr, R. E.; Haegel, N. M.; Kahn, J. M.; Haller, E. E. Beryllium-Hydrogen and Zinc-Hydrogen Shallow Acceptor Complexes in Germanium. Solid State Commun. 1987, 61, 27-32.

(21) Tsai, M. J.; Fahrenbruch, A. L.; Bube, R. H. Sputtered Oxide/Indium Phosphide Junctions and Indium Phosphide Surfaces. J. Appl. Phys. 1980, 51, 2696-2705.

(22) Temkin, H.; Dutt, B. V.; Bonner, W. A.; Keramidas, V. G. Deep Radiative Levels in InP. J. Appl. Phys. 1982, 53, 7526-7533.

(23) Tuck, B.; Hooper, A. Diffusion Profiles of Zinc in Indium Phosphide. J. Phys. D: Appl. Phys. 1975, 8, 1806-1821.

(24) van Gurp, G. J.; van Dongen, T.; Fontijn, G. M.; Jacobs, J. M.; Tjaden, D. L. A., Interstitial and substitutional $\mathrm{Zn}$ in InP and InGaAsP. J. Appl. Phys. 1989, 65, 553-560.

(25) Katz, A. Indium Phosphide and Related Materials: Processing, Technology, and Devices. Adv. Mater. 1993, 5, 228-229.

(26) Grabmaier, J. G. Silicon. Springer-Verlag Berlin and Heidelberg GmbH, Berlin, Germany, 2013.
(27) Warren, C. W.; Li, J.; Wolden, C. A.; Meysing, D. M.; Barnes, T. M.; Miller, D. W.; Heath, J. T.; Lonergan, M. C. The Effect of Copper on the Sub-Bandgap Density of States of CdTe Solar Cells. Appl. Phys. Lett. 2015, 106, 203903.

(28) Miller, D. W.; Warren, C. W.; Gunawan, O.; Gokmen, T. Mitzi, D. B.; Cohen, J. D. Electronically Active Defects in the $\mathrm{Cu}_{2} \mathrm{ZnSn}(\mathrm{Se}, \mathrm{S})_{4}$ Alloys as Revealed by Transient Photocapacitance Spectroscopy. Appl. Phys. Lett. 2012, 101, 142106.

(29) Boucher, J. W.; Miller, D. W.; Warren, C. W.; Cohen, J. D.; McCandless, B. E.; Heath, J. T.; Lonergan, M. C.; Boettcher, S. W. Optical Response of Deep Defects as Revealed by Transient Photocapacitance and Photocurrent Spectroscopy in CdTe/CdS Solar Cells. Sol. Energy Mater. Sol. Cells 2014, 129, 57-63.

(30) Heath, J. T.; Cohen, J. D.; Shafarman, W. N.; Liao, D. X.; Rockett, A. A. Effect of Ga Content on Defect States in $\mathrm{CuIn}_{1-\mathrm{x}} \mathrm{Ga}_{\mathrm{x}} \mathrm{Se}_{2}$ Photovoltaic Devices. Appl. Phys. Lett. 2002, 8o, 4540-4542.

(31) Montie, E. A.; van Gurp, G. J. Photoluminescence of Zndiffused and Annealed InP. J. Appl. Phys. 1989, 66, 5549-5553.

(32) Hsu, J. K.; Juang, C.; Lee, B. J.; Chi, G. C. Photoluminescence Studies of Interstitial $\mathrm{Zn}$ in InP due to Rapid Thermal Annealing. J. Vac. Sci. Technol., B 1994, 12, 1416-1418.

(33) Banerjee, S.; Srivastava, A. K.; Arora, B. M. Thermal Degradation of InP in Open Tube Processing: Deep-Level Photoluminescence. J. Appl. Phys. 1990, 68, 2324-2330.

(34) Swaminathan, V.; Donnelly, V. M.; Long, J. A Photoluminescence Study of Cd-Related Centers in InP. J. Appl. Phys. 1985, $58,4565-4572$.

(35) Mullin, J. B.; Royle, A.; Straughan, B. W.; Tufton, P. J.; Williams, E. W. Crystal Growth and Properties of Group IV Doped Indium Phosphide. J. Cryst. Growth 1972, 13, 640-646.

(36) Pearton, S. J.; Corbett, J. W.; Shi, T. S. Hydrogen in Crystalline Semiconductors. Appl. Phys. A 1987, 43, 153-195.

(37) Holt, D. B.; Joy, D. C. SEM Microcharacterization of Semiconductors. Academic, UK, 1986.

(38) Chen, J.; Sekiguchi, T.; Yang, D.; Yin, F.; Kido, K.; Tsurekawa, S. Electron-Beam-Induced Current Study of Grain Boundaries in Multicrystalline Silicon. J. Appl. Phys. 2004, 96, 54905495

(39) Heitjans, P.; Kr̃ger, J. Diffusion in Condensed Matter: Methods, Materials, Models. Springer, Berlin, Germany, 2005.

(40) Virtuani, A.; Lotter, E.; Powalla, M.; Rau, U.; Werner, J. $\mathrm{H}$.; Acciarri, M. Influence of $\mathrm{Cu}$ Content on Electronic Transport and Shunting Behavior of $\mathrm{Cu}(\mathrm{In}, \mathrm{Ga}) \mathrm{Se}_{2}$ Solar Cells. J. Appl. Phys. 2006, 99, 014906.

(41) Thibault, J.; Rouviere, J.-L.; Bourret, A. Grain Boundaries in Semiconductors, In Handbook of Semiconductor Technology, Wiley-VCH Verlag GmbH, Germany, 2oo8, 377-451. 
1

2

3

4

5

6

7

8

9

10

11

12

13

14

15

16

17

18

19

20

21

22

23

24

25

26

27

28

29

30

31

32

33

34

35

36

37

38

39

40

41

42

43

44

45

46

47

48

49

50

51

52

53

54

55

56

57

58

59

60

Insert Table of Contents artwork here

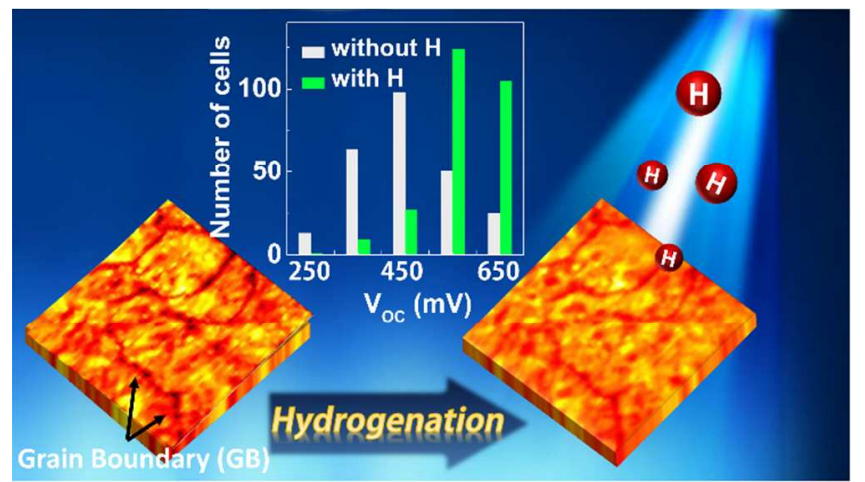

